\title{
Anatomical Variations of Frontal Sinuses Among The Male and Female Genders Living in Karachi
}

\author{
Quratulain Javaid, Ambreen Usmani, Aisha Qamar
}

- - - - - - - - - - - - - - - - - - - - - - - - - - - ABSTRACT

Objective: To determine morphology and variation in dimensions of frontal air sinuses in male and female genders living in Karachi.

Study Design and Setting: It was a cross sectional study and was conducted at Radiology Department, JPMC.

Methodology: The total number of study participants were 216. The research subjects were divided into two equal groups of males and females each having 108 members. The mean age of the participants was calculated to be $35.14 \pm 8.68$ years. The study subjects were recruited from Radiology Department, JPMC, Karachi. After taking written informed consent, Water's (occipito-mental) view radiography was done to measure the parameters of height, width and area of the frontal air sinuses. The included variables were the demographic data and the physical examination to exclude facial anomalies. All the measurements were recorded and the measurements were saved by the help of Radiant DICOM digital software.

Results: The parameters of height, width and the area of frontal sinuses showed highly significant variability on both the right and the left sides. All the dimensions were highly significantly greater in the males as compared to the female study participants $(\mathrm{p}=0.000)$. The Independent-Samples T Test was applied to compare the two gender groups.

Conclusion: The parameters of height, width and area of frontal sinuses were greater in the males as compared to the females on both the left and the right sides.

Key words: Anthropology, Frontal sinus, Sexual dimorphism

\section{INTRODUCTION:}

The humans living in a society have their specific identities. The living individuals are named and they are known to the others by their personal appearances. As the identity of the living is important similarly it is equally vital and essential to know about the identification of the deceased. The deceased need to be identified where there are catastrophes like typhoons, earthquakes, bomb blasts, tsunamis etc. Other major utility is for the medicolegal cases, for social reasons and in cases where financial decision have to be taken. ${ }^{1}$

When dead bodies are in intact shape and organization, they are identified on basis of structural anatomy of face. At instances when the bodies are severely damaged and disguised several methods have to be adopted for the purpose of identification. It has been reported that over a period of last ten years the disaster rate and the causalities related to those incidents have increased. This has created enormous load on forensic science experts as well as anthropologists. The

I - - - - - - - - - - - -

I Senior Lecturer, Anatomy Department

Bahria University Medical and Dental College

Email: docannie2010@gmail.com

I

Ambreen Usmani

Sr Professor and HOD- Anatomy, Vice Principal

I Deputy Director, Medical Education

I Bahria University Medical and Dental College

I Aisha Qamar

Professor, Anatomy Department

Bahria University Medical and Dental College

Received: 17-09-2019

Accepted: 06-12-2019 advancement of the forensic science has made possible for the anthropologists to recognize the unknown individuals with great confidence. ${ }^{2}$ A report on the terrorists activities in Pakistan has mentioned increase in the incidence of such activities from the period of 2011 to 2015 . $^{3}$

The technology involved in forensic anthropology uses the knowledge of the subject of anatomy to ascertain the characteristics and uniqueness of the human body. The investigation requires keen examination of the body's structural organization and details at the spot of the tragic incident. Several years of the researches and experimentations have led to the evolvement of several procedures of human identification. The scientific methods are extremely helpful in situations when the identity becomes a challenge. Soft tissue prints imaging and DNA analysis of the body remains are one of the available methods used by the forensic anthropologists to solve their complex tasks of knowing unidentified bodies. ${ }^{4,5}$ In cases where soft tissue is lost due to the extremes of temperatures or decomposition, anthropological studies depend on the bony structures that are stronger enough to remain intact after fatal disasters. The simple yet cost effective technique of radiology can serve as an effective tool in the process of identification of the victims. ${ }^{6}$ The radiological methods are far cheaper as compared to the other methods of personal identification. Forensic radiology has become an integral component of the forensic science because of its simpler methodology and cost effectiveness. ${ }^{7}$

Among the anthropological identification tools, skulls are helpful in identification. Skull is a part of human body that 
is made of strong connective tissue. It is the second last part to persist after teeth when a person dies. ${ }^{8}$ The parts of the skull have characteristic features which make them one of the valuable sources in cases where the body's soft tissues are lost and it is in decomposed state. ${ }^{9}$ The parts of the skull used for human identification include the nasal septum, mastoid process, sella turcica, teeth and para nasal sinuses. ${ }^{10}$ The superimposition techniques involving the structures of the human skulls have helped in identification of the deceased. $^{7}$

The anatomy of the paranasal sinuses can help the forensic anthropologists in human identification due to the peculiar characteristics which are unique to all the human beings. ${ }^{10}$ The stronger bony identification tools can be identified by a simple and less expensive method called radiography. The methodology of radiography aids in determining the identification of persons that are otherwise in decomposed or putrefied state. ${ }^{11}$

The frontal sinuses anatomy has proven to be useful due to their unique features. ${ }^{12}$ Over the years with the advancements of the techniques and increased research work, usefulness of frontal sinuses anatomy in personal identification cannot be overlooked. Reasearch based on matching and comparison of the frontal sinuses, mentioned the similarity of anatomical structures in terms of the antemortem and the postmortem findings. ${ }^{13,14}$

The terrorists' activities as well as natural disasters are on the rise in Pakistan. According to the Emergency Database (EM-DAT) and Global Terrorism Database (GTD) report, from the period of 2003 till 2017, the number of terrorists activities were 289 in number while the natural disasters were recorded to be $45 .{ }^{15}$ Various researches have been conducted on frontal air sinuses across the world.In Pakistan literature search shows that till now no research paper has been published that was related to the anatomical variation and its significance in the field of anthropology. Since variations are present among the people living across the world, it's important to conduct a study among the males and females of Pakistan and indeed it was the rationale of the study.

\section{METHODOLOGY:}

The study was conducted at the Radiology Department, JPMC. Before commencing the research ethical approval was obtained from the Ethical Review Committee of Bahria University Medical and Dental College and the Institutional Review Board of Jinnah Post graduate Medical Center. The sample size was calculated by the help of open epi version 3 calculator and it was found to be 214 . The total number of the study subjects included in the present study was 216 . The total duration of the study was 6 months and individual study period was 40 minutes for each participant. The research participants were divided into two equal groups of males and females. Each gender sub group consisted of 108 members. The mean age of the participants was calculated to be $35.14+8.68$ years.

The study subjects were recruited from the Radiology Department of Jinnah Postgraduate Medical Center, Karachi. Males and females free of paranasal diseases within age range of 20 to 50 years were included in the research. Participants who gave past history of paranasal sinus diseases or who had surgeries of paranasal sinuses and pregnant ladies were excluded from the research. Written informed consent was obtained before the study. The included variables were the demographic data and the physical examination to exclude facial anomalies. The present study included the research subjects above 20 years in order to include individuals with full frontal sinus development. The participants were physically examined before they were selected for radiography. The view used for radiography was Water's (occipito-mental) view. The radiographic procedure for the frontal sinus imaging was carried out in the room number 2 of the radiology department. The participants were asked to stand erect with chin raised. The distance was $36 \mathrm{~cm}$ from source to film.The X-ray beam was at right angle to the receptor and 45 degrees to the orbito-meatal line. The X-ray beam was inclined 1 inch above the level of external auditory meatus. The study parameters were height, width and area of the right and left frontal air sinuses. The parameters were saved in the JPEG format and then the measurements were carried out by the help of Radiant DICOM digital software.

The measurements were performed according to the Ribeiro's criteria. ${ }^{16}$ Base line A was drawn on the upper limit of both the orbits. The highest point of the right frontal sinus was marked as $\mathrm{B}$. A perpendicular line $\mathrm{C}$ was drawn from the highest point of right frontal sinus to the base line $\mathrm{A}$. The perpendicular line $\mathrm{C}$ was considered as the height of the right frontal sinus. The highest point of the left frontal sinus was marked as D. A perpendicular line $\mathrm{E}$ was drawn from the highest point of left frontal sinus to the base line A. The perpendicular line $\mathrm{E}$ was considered as the height of the left frontal sinus. Line passing at the most lateral point of right frontal sinus was marked as F. A perpendicular line G represents maximum distance drawn from the most lateral point of right frontal sinus to the midline septum. The perpendicular line $\mathrm{G}$ was considered as the width of the right frontal sinus. Line passing at the most lateral point of right frontal sinus was marked as $\mathrm{H}$. A perpendicular line I represents maximum distance drawn from the most lateral point of left frontal sinus to the midline septum. The perpendicular line I was considered as the width of the left frontal sinus. Right area of the frontal air sinus was calculated as a product of right height and right width. Left area of the frontal sinus was calculated as a product of left height and left width.

SPSS version 23.0 was used for analysis of the data. The Independent $\mathrm{T}$ Test was used to compare the gender groups. 
The continuous data was reported as mean \pm SD. The results were regarded as significant when the $\mathrm{p}$ value was $<0.05$. The result were regarded as highly significant when the $p$ value was $<0.001$.

\section{RESULTS:}

The total study participants were 216 in number. They were divided into two equal groups of male and female genders with 108 participants in each sub group. When mean heights of the right and left frontal sinuses were compared between the male and female gender groups, highly significant variations were noted for both the right and left frontal air sinuses. Statistically, males have significantly higher height than females on both the right and the left sides (Table 1).

When mean widths of the right and left frontal sinuses were compared between the male and female gender groups, highly significant variations were noted for both the right and left frontal air sinuses. Statistically, males have significantly higher width than females on both the sides (Table 2).

Table 1: Gender wise comparison of mean heights of right and left frontal sinuses

\begin{tabular}{|c|c|c|c|}
\hline Parameter & Gender & Mean \pm SD & P value \\
\hline \multirow{2}{*}{$\begin{array}{c}\text { RT Height } \\
(\mathrm{cm})\end{array}$} & Male & $2.30 \pm 0.70$ & \multirow{2}{*}{$0.000^{* *}$} \\
\cline { 2 - 4 } & Female & $1.97 \pm 0.62$ & \\
\hline \multirow{2}{*}{$\begin{array}{c}\text { LT Height } \\
(\mathrm{cm})\end{array}$} & Male & $2.63 \pm 0.66$ & \multirow{2}{*}{$0.000^{* *}$} \\
\cline { 2 - 3 } & Female & $2.30 \pm 0.63$ & \\
\hline
\end{tabular}

RT Height: Right frontal sinus height

LT Height: Left frontal sinus height

Test applied: Independent Samples T Test

Table 2: Gender wise comparison of mean widths of right and left frontal sinuses

\begin{tabular}{|c|c|c|c|}
\hline Parameter & Gender & Mean \pm SD & P value \\
\hline \multirow{2}{*}{$\begin{array}{c}\text { RT Width } \\
(\mathrm{cm})\end{array}$} & Male & $2.72 \pm 0.65$ & \multirow{2}{0}{$0.000^{* *}$} \\
\cline { 2 - 3 } & Female & $2.41 \pm 0.60$ & \\
\hline \multirow{2}{*}{$\begin{array}{c}\text { LT Width } \\
(\mathrm{cm})\end{array}$} & Male & $3.53 \pm 0.65$ & \multirow{2}{*}{$0.000^{* *}$} \\
\cline { 2 - 3 } & Female & $3.21 \pm 0.61$ & \\
\hline
\end{tabular}

RT Width: Right frontal sinus width

LT Width: Left frontal sinus width

Test applied: Independent Samples T Test

Table 3: Gender wise comparison of mean areas of right and left frontal sinuses

\begin{tabular}{|c|c|c|c|}
\hline Parameter & Gender & Mean \pm SD & P value \\
\hline \multirow{2}{*}{$\begin{array}{c}\text { RT Area } \\
(\mathrm{cm})\end{array}$} & Male & $6.58 \pm 2.89$ & \multirow{2}{*}{$0.000 * *$} \\
\cline { 2 - 3 } & Female & $5.05 \pm 2.30$ & \\
\hline \multirow{2}{*}{$\begin{array}{c}\text { LT Area } \\
(\mathrm{cm})\end{array}$} & Male & $9.66 \pm 3.60$ & \multirow{2}{*}{$0.000 * *$} \\
\cline { 2 - 4 } & Female & $7.70 \pm 3.01$ & \\
\hline
\end{tabular}

RT Area: Right frontal sinus area

LT Area: Left frontal sinus area

Test applied: Independent Samples T Test
When mean areas of the right and left frontal sinuses were compared between the male and female gender groups, highly significant variations were noted for both the right and left frontal air sinuses. Statistically, males have significantly higher area than females on both the sides (Table 3).

\section{DISCUSSION:}

The identification of the victim is a difficult task when mass destructions and explosions occur. The identity can be established by several methods depending on the status of the dead body. In cases when there are soft tissues available, finger printing and DNA analysis can be done. On the contrary, when there are skeletonized bodies, the available option remains the identification of the deceased through unique features of the bones. Antemortem comparison of the deceased structures with that of the postmortem remain the cornerstone of identification. DNA analysis is possible by the help of polymerase chain reaction. The extreme heat as present in blasts and mass explosions can interfere with the quality of sample available for DNA analysis. ${ }^{4,5}$ In cases of skeletonized bodies, frontal sinus anatomical details examination by radiography is a simple yet authentic method for identification.

Frontal sinuses have unique configuration in every individual. The variation in the anatomical configuration of the frontal air sinuses was observed in a research on the Mexican adults. No two frontal sinuses have the same measurements and therefore they are considered to be one of the best tools in identification of the unknown dead bodies. ${ }^{17}$ The present study has also documented variability and unique features between the male and female genders.

The present study included the study subjects in between the age groups of twenty to fifty years. Similar age range was considered as an inclusion criteria in a study on Iranian adults. ${ }^{18}$ It has been observed that the developmental period of the frontal air sinuses is completed by the age of fourteen years. ${ }^{19}$ According to the published researches, the development of the frontal air sinuses is completed by the age of twenty years. ${ }^{20,21}$ The present study included the research subjects above 20 years in order to include individuals with full frontal sinus development. A research article has documented that age related changes occur in the frontal air sinuses after the age of $60 .^{22}$ This is the reason to keep the maximum age limit to 50 years so that normal anatomical morphology can be observed.

The dimensions of the frontal air sinuses in the present study were found to be different when males were compared with the females. The parameters were observed to be greater in dimensions for the males as compared to the females who participated in the present research. A research article published in the Journal of Forensic Radiology and Imaging mentioned about a study that was conducted on the Egyptian population. It was documented that significant difference 
in the dimensions between the males and the females were also observed. ${ }^{23}$

In our study, the mean heights of the right frontal air sinuses were found to be greater in the males as compared to the females study participants. Variations in terms of mean heights were also recorded when left frontal sinuses were compared between the two genders. Similar results were shown by the researches conducted in India in which the dimension of the right and left frontal sinuses heights in males were bigger as compared to that of the females in the study and the results were statistically significant both on the right and the left sides. ${ }^{17}$ Previous studies on the adults of Nigeria also showed parallel findings with documented greater dimensions for the males as compared to the females. The results were found to be significant on the left sides and they were non-significant on the right side. ${ }^{24}$ These variations in height observed in the present study can be attributed to the differences in the general structural anatomy and the growth between the two genders. ${ }^{25}$

The current study has showed that the mean widths in males are bigger in dimension in the males in comparison to the females both for the right and left frontal sinuses. The present study's result are in concordance with a morphometric study done on the adult individuals of Karnataka. The mean widths of males were bigger in dimension as compared to the females but the results were statistically significant only on the left side and the right frontal sinuses mean width documented non-significant differences. ${ }^{26}$ Comparable findings were observed in between the males and the females of Kashmir with significant results both for the right and left frontal sinuses mean widths. ${ }^{27}$ Craniofacial architecture contributes in determining the size of the frontal sinuses. The size of the bones differ between the two genders. Greater the size of the frontal bone, greater will be the size of the frontal sinus. The facial architecture is larger in the males than the females. ${ }^{28}$ This could be the explanation of wider widths of frontal air sinuses in the males in contrast to the size of widths in the females.

In the present study, the mean area of the left frontal sinus in the males was measured to be bigger in dimension in the males when the data was evaluated against the females. Analogous findings were observed in the researches conducted on individuals of Turkey with significant results both on the right and the left sides of the frontal air sinuses. ${ }^{29}$ A research conducted in Moradabad, India documented contrary findings to the findings of the present study. The mean area reported for the females on both the right and the left sides of frontal air sinuses documented comparatively bigger dimensions for the females as compared to the male study participants but the results were not statistically significant. ${ }^{30}$ The smaller areas in females compared to the males may be due to the overall anatomical variability between the two genders.

\section{CONCLUSION:}

The parameters of the height, width and area of frontal sinuses were greater in the males as compared to the females on both the left and the right sides in the males and females living in Karachi.

\section{REFERENCES:}

1. Kumar R, Athota A, Rastogi T, Karumuri, S K. Forensic radiology: An emerging tool in identification. JIAOMR 2015;27(3):416-22.

2. Konigsberg LW, Jantz LM. The probabilistic basis for identifying individuals in biohistorical research. Studies in Forensic Biohistory. Anthropol P 2017;75:213-7.

3. Choudhary A, Lemos R, Van Reenen J. Management in Pakistan: Performance and conflict. IGC 2017;89451:1-46.

4. Dhall JK, Kapoor AK. Fingerprint ridge density as a potential forensic anthropological tool for sex identification. JFS 2016;61(2):424- 29 .

5. Calafell F, Larmuseau MH. The Y chromosome as the most popular marker in genetic genealogy benefits interdisciplinary research. Human genetics 2017;136(5):559- 73.

6. Tarani S, Kamakshi SS, Naik V, Sodhi A. Forensic radiology: An emerging science. JACRI 2017;4(2):59-63.

7. Raina A, Ravindra SV, Malik U, Yeluri G. Imaging In Identification. Pearl Dent 2019;9(3):1-5.

8. Silva RF, Mundim MBV, Picoli FF, Franco A. Dental identification of a mummified body using dental cast and prosthesis. J Forensic Investigation 2015;3(2):1-3.

9. Cox M, Malcolm M, Fairgrieve SI. A new digital method for the objective comparison of frontal sinuses for identification. JFS 2009;54(4):761-72.

10. Sherif NA, Sheta AA, Ibrahim, ME, Kaka RA, Henaidy MF. Evaluation of the paranasal sinuses dimensions in sex estimation among a sample of adult Egyptians using multidetector computed tomography. J. Forensic Radiol. Imaging 2017;11:33-9.

11. Kanjani V, Rani A, Kanjani D. Morphometric analysis of the orbital aperture in North Indian Population: A retrospective digital forensic study. JABMR 2019; 9(2):85-9.

12. Gadekar NB, Kotrashetti VS, Hosmani J, Nayak R. Forensic application of frontal sinus measurement among the Indian population. JOMP 2019;23(1):147-51.

13. Belaldavar C, Kotrashetti VS, Hallikerimath SR, Kale AD. Assessment of frontal sinus dimensions to determine sexual dimorphism among Indian adults. JFDS2014;6(1):25-30.

14. Tiwari P, Bhovi TV, Jaju PP, Gupta M, Shrivastava K. Frontal Sinus-A Useful Personal Identification Tool. JOMOOOR 2016;2(1):11-22.

15. Najam, N. U. S., \&Mehmood, A. M. (2019). The economic cost of terrorism and natural disasters:A deeper analysis of the financial markets of Pakistan. Online 2019 cited 201904 11. Available from https://mpra.ub.uni-muenchen.de/92278/

16. Ribeiro Q, DeAndrade F. Standardized measurements of radiographic films of the frontal sinuses: An aid to ENT. ENTJ 2000;79(1):26-8.

17. Galán A, Carlos J, Reyes TG. Anatomic evaluation and description of the frontal sinus in the Mexican population between 20 to 60 years old through computed tomography. Archivos De Neurociencias2016;21(1):23-31. 
18. Nateghian Z, Abedi I, Dashti GH, Faraji B. Frontal Sinus Pattern and Evaluation of Right and Left Frontal Sinus Volume According to Gender, Using Multi Detector CT Scan. JFSC 2016;4(4):1-4.

19. Moore K, Ross A. Frontal sinus development and juvenile age estimation. The Anatomical Record 2017;300(9):160917.

20. Nikam SS, Gadgil RM, Bhoosreddy AR, Shah KR, Shirsekar VU. Personal identification in forensic science using uniqueness of radiographic image of frontal sinus. JFOS 2015;33(1):1-5.

21. Marsya G, Sasmita IS, Oscandar F. Overview of the frontal sinus anteroposterior size based on against lateral cephalometric radiographs chronological age as forensic identification. PJD 2017;29(2):113-17.

22. Demiralp K, Cakmak S. K, Aksoy S, Bayrak S, Orhan K, Demir P. Assessment of paranasal sinus parameters according to ancient skulls' gender and age by using cone beam computed tomography. Folia Morphologica 2018;5603: 89-92.

23. Motawei SM, Wahba BA, Aboelmaaty WM, \&Tolba EM. Assessment of frontal sinus dimensions using CBCT to determine sexual dimorphism amongst Egyptian population. JFRI 2016;6:8-13.
24. Eboh DE, Ogbeide OU, Ivwighren T. Radiographic anthropometric study of frontal sinus for sex determination in Benin city, South-South Nigeria. JFDS 2017;9(1):31-5.

25. Standring S, editor. Gray's anatomy: the anatomical basis of clinical practice. $45^{\text {th }}$ ed. Elsevier Health Sciences; 2015: p.556-7.

26. Soman BA, Sujatha GP, Lingappa A. Morphometric evaluation of the frontal sinus in relation to age and gender in subjects residing in Davangere, Karnataka. JFDS 2016;8(1):57-61.

27. Chalkoo AS, Sharm P, Nazir N, Tariq S. Evaluation of the frontal sinuses dimensions in sex estimation among a sample of adult Kashmiri population using multidetector computed tomography. IJMI 2018;4(4):122-5.

28. Tehranchi A, Motamedian SR, Saedi S, Kabiri S, Shidfar S. Correlation between frontal sinus dimensions and cephalometric indices: A cross-sectional study. Eur J Dent 2017;11(1):64.

29. Buyuk SK, Simse H, Karaman A. The relationship between frontal sinus morphology and skeletal maturation. FOLIA MORPHOL 2018;77(3):503-8.

30. Kaur N, Sunira C, Parvathi D, Raju M, Neeraj T, Ruhi S. The forensic importance of frontal sinus in gender discrimination: a morphometric study. JOS 2013; 5(1):2-5. 